\title{
The Arras MS. of Herbert of Bosham
}

The third volume of the Materials for the History of Thomas Becket, archbishop of Canterbury, edited by the late Canon J. C. Robertson for the Rolls Series, contains the life of the archbishop by Herbert of Bosham. The main authority used by the editor is the Arras MS. (Bibl. de la Ville, 649), which unfortunately was mutilated by an unscrupulous librarian, who is: said by Dr. Giles to have removed every tenth leaf. ${ }^{x}$ Robertson accordingly supplemented it by making use of a manuscript which formerly belonged to the monastery of Aulne, but which afterwards found its way into the collection of Sir Thomas Phillipps (no. 4622). This is, however, only an abridgement. But Sir Thomas Phillipps also recovered some of the missing leaves of the Arras MS. itself. About these Dr. Giles says,

I have been informed by Sir Thomas Phillipps, Baronet, whose splendid collection of MSS. is an honour to himself and to the nation, that in passing through Arras many years ago, he was so fortunate as to recover the very leaves which had been cut out by the librarian, of Herbert de Bosham's Life of Becket, and that the authorities of Arras declined to. repay him the small sum of money which he gave the tailor from whom he purchased them, choosing rather to have their valuable volume imperfect, and to suffer the recovered leaves to be conveyed to England. The most unlucky part of this story is, that Sir Thomas Phillipps has since mislaid these leaves, and as yet is unable to discover in what part of his. immense library they have been misplaced. ${ }^{2}$

Fortunately Sir Thomas Phillipps wrote two letters to Mr. Henry Petrie, the keeper of the records in the Tower, dated 'Rouen 7 December 1828 ' and '. . . 1829', describing his discovery and giving a transcript of considerable portions of the leaves recovered. These agree to some extent with the Aulne MS., but contain long passages which it omits. I give below a copy of these passages, and a collation of Sir Thomas Phillipps's transcript with the printed text where the readings differ. Dots are placed at the end of the fragment where there appears to be a gap not filled up : where there is no gap the next word of the printed text is added in brackets. The punctuation and capitals of the transcript have not been exactly followed. The two letters are now preserved among the Petrie transcripts presented by Miss Sharpe to the Public Record Office. I should like to acknowledge the great assistance I have received from Mr. Charles Johnson of the Public Record Office in deciphering a large number of the words.

Theodore Cratb. 
Page 177, line 5 from the bottom, after aculeum add $\mathrm{Ni}$ fallor hic certe serpens aut verus scorpio, aut scorpionis est frater. De quo ad prophetam Dominus 'Et cum scorpionibus', inquit, 'hsbitstio tus'. De qualibus et Psslmista 'Intenderunt', inquit, ' archum rem amaram, ut sagittent in occultis immaculatum'. [Verum, \&c.]

Page 177, bottom line, after pertranseo add Suo quippe tempore revelabitur, quem ad modum hystorici cantici huius declarabunt sequentia (in margine iii Tho. . . om enim serpens): nisi quia etsi dictu turpe sit et horrendum, non possum hic non interserere quod nos vidimus et experti sumus de verme hoc. Qui stellione perniciosior non solum moratur in domibus regum, sed et pontificum. Siquidem a palatiis secularium ad palatia ecclesiasticorum principum serpendo sensim, ascendit, occupans et heec et illa qussi sicnt aulam et ecclesiam. Cuius toxico nostri officii viri [sic], clericos dico, passim nimis infectos video. Ipsis etiam in palatiis pontificum sicut et secularibus in anlis regum contendentibus inter se, quis eorum videatur maior, non in hoc successores spostolorum, sed potius Galileorum piscatorum pauperum et pannosorum adhuc ; nostris, inquam, contendentibus non forte clamosa voce ut pannosi illi nichil habentes quorum etiam omnium magister erat minimus, sed hii nostri et corde et opere manifesto contendunt inter se, quis cui preponi possit, quis in mensa discumbat propior, ad concilia vocetur prior, in colloquio seorsum sit frequentior, ad potiora beneficia cum vacaverint iudicetur dignior. Ut ita per Domini sui gratiam et es quae sua sunt quaerant pariter et mundi glorism assequantur. Et ut de aliis nunc talium moribus tacesm novi mores hominum hos ut qui aliquandin inter ipsos et de ipsis. Tunc certe ego et mei similes in pomps et luxu seculi, inter epularum varietates et vina, duarum sororum Cenodoxiae et Castrimargiae brachiis amplexi, magistri illius immemores : 'Honore ', inquit, ' invicem praevenientes.' Et non efficiamur inanis gloriae cupidi invicem provocantes invicem invidentes. Sed meum quondam et mei similium aulicum vermen [sic] hunc, ecclesiasticum dicere vereor, non quero nunc exagitare amplius, ipsius virus calsmo meo aut stilo fortius exprimendo. Solum ipsum hic tetigisse sufficiat, ipso suo tempore revelando, revelabitur enim adhuc ut pretetigimus, calamo nostro ipsius virus tunc expressavi fortius, quo ipse nos tunc sicut pernitiosius est puncturus, et apertius.

Incipiunt capitula tercii thomi.

2. After cancellarius add ad sedem illam.

3. After reversus add et quomodo discipulo qui scripsit haec visionem retulerit et quid ei iniunxerit.

4. After consecratus add et a quo et quo tempore et de ad Romanum Pontificem propter pallium missis.

5. After consecrsti add antistitis in virtutibus novitatem describere et tamen describat.

6. After veteri add homine induerit novum, et de utroque ipsius scemate et corporali et spirituali.

7. Quomodo triplex psuperum mensa ponebstur cotidie et primo de prims-mense in qua ipse pontifex noctibus duntsxat discumbentibus ministrabat et de causa mense huius. 
8. Secundo de $2^{\text {da }}$ simul etism et de $3^{\text {tia }}$ mensa cotidisna in quibus non ipse pontifex sed fratres duo ad quos de egenis pertinebat ministrabant et de mensarum causis.

9. De duplici pontificis mensa spirituali post istas corporum mensas.

10. De prima sacrae scripturae mensa et qualiter et quam attente in ea pontifex discubuerit et quare.

11. De secunda altaris mensa et qualiter et quam devote in hac discumbere consueverit.

12. De mensa corporali in qua ipse pontifex discumbebat post duas illas spirituales: nisi quia prius ostenditur qualis fuerit in iudiciis quibus cotidie spirituales post mensas, priusquam in mensa corporali discumberet, intendebat.

13. De mensa corporali in qua ipse pontifex auditorium egrediens cum suis mox discumbit et qualiter et quam sobrie et quam urbane et quam magnifice discubuerit in mensa hac.

14. De mensa iterum altaris spirituali, quales in ea dispensatores ordinare studuerit et quam pavidus et quam solicitus in ordinandis extiterit.

15. De morosa ad describendum pontificis opera dilatione, se excusat discipulus eo quod non solum opera sed et cansas operum quas nonnullas ab ipso pontifice edocente didicerat, describat.

16. De questionibus quas movit pontifex illis qui possessiones ecclesiae suae detinebant iniuste; et de primo adventu Regis in Angliam post consecrationem pontificis.

17. De profectione pontificis tempore $3^{\text {tii }}$ Alexandri Papae ad Turonense Concilium, et qualiter et quam magnifice in via ab omnibus sit exceptus et maxime cum Turonis pervenisset, et quod in Angliam prospere sit reversus, et quod reversus duos episcopos consecraverit, et monasterium illud nobile et regale de Redinges dedicaverit. Et similiter Londoniae in preclaro illo monasterio quod dicitur Wemustier [sic] beatum Regem Edwardum canonizatum, inter sanctorum corpora collocaverit.

18. De dissensione inter regem et archipresulem et prima dissensionis causa ; ubi etiam inter initia breviter tangit nonnulla de his mala quae ex dissensione hac [pervenerunt, \&c.].

[finis primi folii fragmentorum.]

Page 200, line 4 from bottom, after adimplebatur add Inter caetera quippe humilitatis opera, humilis haec et devota pedum ablutio, aqua haec salubris, quae primo ex ipso humilitatis fonte Christo emanavit; quia iam non suprema sed extrema et infima pannosi corporis abluuntur in paupere; nullum inquam inter humilitatis opera, quod ita cordis contritionem generet, carnis fervorem temperet, et totius indecoris in carne pruriginem fuget. Nichil quod ita torpentes spiritus excitet, arida corda imbuat, et totius interioris hominis augeat devotionem. Hoc quod dicimus norunt melius qui in hoc humilitatis opere versantur frequentius. Nec enim frustra rex ille virtutum maiestatis Dominus ponit vestimenta sua, et praecingens se, quorundam panposorum advolvitur pedibus ipsos lavans sic; nisi quis ipse scientiarum et virtutum fons Dominus apprime novit aquam hanc abluentem ex se ipso humilitatis fonte emanantem propter 
tantam humilitatis abiectionem plurimum habere virtutis. Unde et idem scientiarum Dominus, Magister magistrorum, cum baptismum primum solo verbo instituerit, istud pedum lavachrum quasi secundum baptismum et verbo substituit, et ipso etiam opere per semet ipsum confirmavit. Suorum quippe neminem, immo nec aliquem legitur seu etiam creditur suo primo baptizasse baptismo. At postquam ipsemet suorum abluerat pedes, primo baptismo hunc quasi secundum mox verbosubstituens, adiecit 'Exemplum', inquiens, 'dedi vobis ut quemadmodum feci vobis et vos faciatis'. Baptizavit igitur hoc secundo baptismo suos, sed primo suo neminem. Solus tamen ipse, omnes baptizans; et in fine quidem commendans hoc humilitatis lavachrum quasi consummativam prioris et consecutivum baptismum, 'Qui', inquit, 'lotus est non indiget nisi ut pedes lavet, sed est mundus totus'. Et propterea hoc humilitatis lavachrum inde certo certius virtutis in se habere plurimum, quod velut e duobus exitibus, verbi, viz. et operis, ab ipso humilitatis fonte Christo emanarit. Quod, sicut iam praeloqui cepimus, animam sicut terram sine aqua pullulare et germinare facit et florere, et fructificare quidem in tempore suo, si tamen frequentetur pro tempore. Et si adhuc dubites, ad Dominum discumbentem in domum Pharisei ingredere, et videbis quod mulier quaedam peccatrix quam supra tetigimus, istam ibi pedibus Domini dat aquam, et mox accipit veniam. Domino in discubitu quasi improperanto Phariseo quod aquam hanc ad prandium invitato non dederit. 'Intravi', inquit, 'in domum tuam, aquam pedibus meis non dedisti.' Et ne ad huius argumentum fidei longius recurratur, vide hanc nostram novam arborem, pro qua totus hic sermo; novum; viz. nostrum Pontificem, vide, inquam, et attende, quia ex aqua hac ex ipso humilitatis fonte emanante, arbor haec nostra . . .

\section{III}

Page 256, line 17, after subsidia add De qualibus et Magister, 'Ante quorum ', inquit, 'oculos Iesus Christus proscriptus est.' Pauperibus et mendacis [sic] nudatis sic, et si non ore, corde tamen et opere cotidie reclamantibus et quasi altissimi auditorium appellantibus, quod ipsis tabida egestate confectis, ipsorum facultates per annos in regum thesauros reponantur. Et, quod accedit imposturae, sunt et plerique principum, qui vacantium ecclesiarum bona etiam sibi hereditarie competere asserant, et ut ea quasi dominica sua et propria percipiant, utantur, fruantur, vertant, convertant, et dispensent pro libitu. Forte quia sliqui decessorum suorum qui quondam velut fulgura, sed iam pertransierunt quasi nunquam fuerint ut nubecula, primo usurpaverunt sic, et isti qui successerunt, nunc hoc ipsum quasi sacrilegium hereditarium vendicant. Hii profecto, quod homine melius novit Deus, graviter in duobus reprehensibiles, tum quod tam longo vacantes sic detinent, tum quia spreta ipsa ecclesia, ipsius bona in usus alienos sic convertere non verentur. Qui utinam sic tenerent eas diutius, ut qui ad ipsius regimen plus foret idoneus, tanto temporc inquirerent studiosius. Quid autem aliud est, sibi sic iure hereditario Crucifixi vendicare et tenere patrimonium quam hereditate Dei possidere sanctuarium ? Unde utrunque coram Deo abhominatio et divinis sancionibus adversum penitus res pauperum et sic hereditarie vendicare et per tempus et tempora sic tenere. Quod vel tenuiter in sacris scripturis erudito 
apertissime claret. Si enim ut sacrilegi enormiter rei sunt, qui aurea vass et argentea et varism templi supellectilem asportaverunt reges ethnici, quid hii faciunt reges nostri Christiani, reges Christi ? nli asportaverunt quae erant ad actualis templi decorem, sed isti quae sunt ad spiritualis templi necessitatem. 'Templum enim Dei', dicit Magister, 'sanctum est, quod estis ros.' Ethnici illi asportarunt, que Rex suus Salomon de tanta sus habundantia et in tanta sua gloria obtulit. Sed isti qui [sic] per proprium sudorem suum et sanguinem Rex suus Christus in cruce adquisivit, et unde illi qui in eterna tabernacula sunt iam recepti fecerunt sibi amicos de msmmonâ iniquitatis. Et hoc quidem principali et regiae presertim magnificentise indecens admodum et inglorium, si hic iniquitatis Mammona in Regum thesauris recludatur. Aututibi hae defunctorum reliquiae, quasi siliquae quaedam, vel quisquiliae, inter vass aurea et argentea et lapides preciosos reponantur. Quid enim peccstis populorum et lacrimis pauperum ad thesauros Regum ? Pars, inquit doctorum unus, sacrilegii est, rem pauperum non dare pauperibus. Et quod adhuc, ut diximus, plus malum cumulat, sunt qui hereditate possidere quaerunt, et hoc iure possidere se dicunt, haec peccata mortuorum et pauperum lacrimas has. Mira quidem, angustalis hereditas haec; et potest esse quod lucrosa ; sed si praeclara, mundus novit, ipsimet iudicent. Unum scio quod nec in arcu nec in gladio nec in ipøorum principum qui sic possident sudore bellico vel sgone, haec ipsis sit adquisita hereditas. Unde ab ipsis ex his nec etiam elemosinae Deo fiunt acceptae, non magis quam si nudato et spoliato altarium uno [operiatur, \&c.].

\section{IV}

Page 290, line 9, after dignnm add 'De hac sede illud dictum antiquum in me iam expertus quae sanctam invenit aut sanctam facit ant abicit. Ego quippe iam a Deo derelictus et ab hac sede videor mihi abiectus. Ecce enim quia formam iurisiurandi cira nos a sanctis patribus introductam et Ecclesiae communem et usitatam in clero, a quibusdam impulsus et eversus mutavi, et verbum illud, scilicet "salvo ordine", tacui. Unde et omni iure ordinis privilegio privari debuissem qui metu aut gratia ordinis mei suppressi privilegium, ponens lucernsm sub modio, candelabro superponendam. Et hoc quidem iam primum peccatum, quod sui pondere mox traxit ad aliud. Ecce enim quia declinavi incontinenti post, in obligationem et novam et novo iuramento firmatam. Unde et iustissimum ut me Dominus cum operantibus iniquitatem adducat. Ecce duo quorum utrumque iam contra solitum admisi et contra debitum. Praeterea quasdam adinventiones in domini mei regis ef mei odium excogitatas, quas et regias consuetudines nominant, suscepi. Quas quidem in ipsorum emulorum oculos abiecisse debueram, nisi quia mecum crusam mesm scriptam porto. Pro qua certissime scio nec dubito, expedit ut aliquo tempore moriar, ne ecclesia pereat. Et quod adhuc grave, quia in predictis non solus cecidi, sed confratres meos primogenitos meliores me, coepiscopos dico meos, mecum traxi in foveam, factus eis in ruinam quibus in resurrectionem esse debuissem. Grave etiam successoribus meis induxi onus, et grandem operam ut evellant, destruant, dissipent et eradicent quae ego male plantavi. Michi itaque vae! et vae! ecclesiae pro me. Accedit 
etiam doloris cumulo, Rex meus et dominus meus a me adeo dilectus, et sicut novit mundus et probaverunt opera, me adeo diligens, verum nunc per utriusque emulos operarios subdolos inter me et ipsum chaos magnum firmatum, non ism fomes sed dissensionis et scismatis inter nos plens et ampla materia et perpetua quoad vixero ego. Unde et lugeo regem cordis mei, regem quem tanquam cor meum, tanquam animam propriam diligebam. Video quippe motam perpetuae, ut iam diximus, dissensionis materiam. Inter regnum enim et sacerdotium de consuetudinibus presertim mots quaestio, lis solet esse immortalis, nisi forte regum clementis indulgest et liberet ecclesiam, aut ecclesia liberetur per sanguinem. Nec igitur mirum si confundor nunc et contristor. Flebilis est enim sicut cernis, confusionis materia et grandis causa. Hinc enim interiora cordis amor regis penetrat, quem tamen iam perdidi, huic ecclesiae Dei mihi commissae totis miserationis visceribus compatiens quam in eis sum ut videor exigentibus peccatis perditurus.' Et cum de Rege et Ecclesia et de his quae acciderant loqueretur sic, ceperunt mox crebro erumpere lacrimae et singultus magis prodire quam verba. Quem cum discipulus, quem supra diximus, accessisse collacrimans et ipse demulcere attemptaret, adiecit 'Immo' inquit 'quis dabit capiti meo aquam et oculis meis fontem lacrimarum et plorabo? Plorabo, inquam, Regis quemadeo diligebam perpetuo amissam gratiam et Ecclesiae per me destructae ruinam irreparabilem. Quare igitur appulsus ab uberibus, ablactatus a lacte? Quare exceptus genibus? Quare conceptus in utero non statim perii? Qui utinsm conceptus essem ne oculus me videret.' Et dum dolor urgeret sic, iam exitus aquarum deduxerunt oculi eius, ita -ut inter continuas lacrimas singultibus crebro erumpentibus, compelleretur rumpere magis sermonem quam finire. Hic est discipulus qui testimonium perhibet de his, et vidit et scripsit haec, qui ad magistrum presumpsit in via accedere, et meruit audire haec. Qui audiens haec et videns sic et toto corde compatiens, mox cogitavit in corde suo, verissimum illud sapientis elogium, quod iustus in principio sermonis accusstor sit sui. Unde et in sermone [novissimo, \&c.].

\section{Table of Textual Variations}

Page 177, line 5 from bottom, after aculeum add Ni fallor, \&c. See I, above.

Page 177, bottom line, after pertranseo add Suo quippe, \&c. See I, above.

Page 199, line 5 from bottom, for sine read si in.

" " " 4, " omit ut plerumque contingebat.

" " "2, " for tunc read tt (tanta).

" 200,7 , for inquit read inquiens.

" , , 11 from bottom, after exemplaris add 'Imitatores', inquit, 'fratres, mei estote, et ita ambulate sicut habetis formam nostram'.

Page 200, line 4 from bottom, after adimplebatur add Inter caetera, \&c. See II, sbove.

Page 226, line 5, after ignoretur add Praeterea nec adeo bestialis erit corporum hic discubitus quin ex eo et etiam in eo vel aliqua spiritui refectio ministretur. Itaque ad hanc accedant, si placet, invitati pontifices. 
Page 226, line 9, after quem add iam.

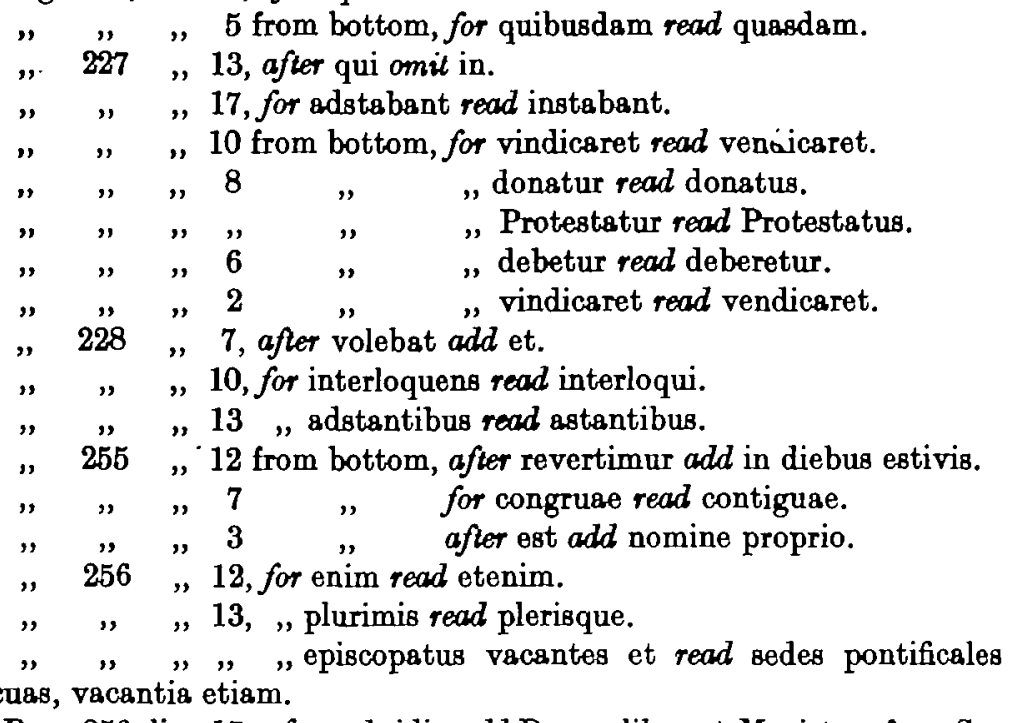

Page 256, line 17, after subsidia add De qualibus et Magister, \&c. See III, above.

Page 289, line 12 from bottom, for praedecessores read decessores.

" " " , "

" " " $11 \quad$ " for etiam inter hostes eius read et inter eius hostes.

Page 289, line 8

decessores mei.

" $, \quad, \quad, \quad 5$

" ,, 3

", ", , for quam read tam. after utinsm add prius. for essem read fuissem.

", quia read qui.

". praedecessores mei read patres mei
Page 289, line 2 from bottom, after hoc read ad sedem hanc.

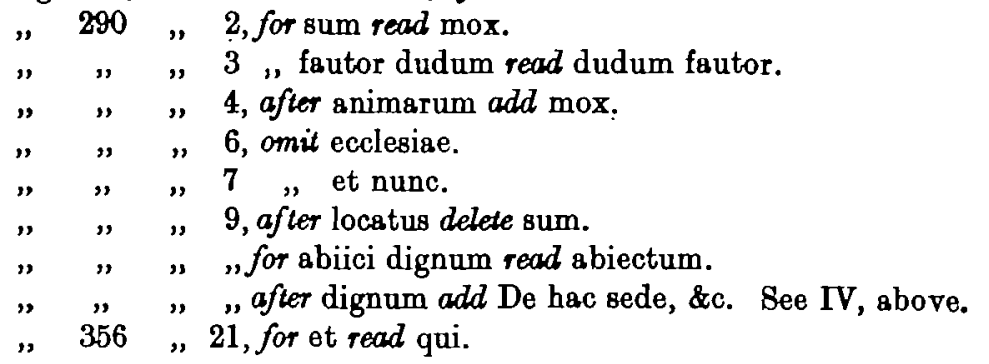

\section{The Date of the Emperor Henry VII's Birth.}

THE date of the Emperor Henry VII's birth would not have loomed so large in the discussions of historians if it had not been for a statement made by Albertus Mussatus. In chronicling 